\title{
Performance Target Setting System and MoU Experience in India
}

\author{
Ram Kumar Mishra, Geeta Potaraju \\ Institute of Public Enterprise, Hyderabad, India
}

\begin{abstract}
In order to make state-owned enterprises (SOEs) more efficient, countries around the globe introduced a system called Performance Contracting System which brought in focus on the results and achievements of a public enterprise and put them on a path of financial profitability. In India, this system was called as the MoU (memorandum of understanding) system and was introduced with an intention to bring in greater focus in the working of the enterprises and in turn maximize benefits for their shareholders. One of the most critical ingredients of the MoU system is identifying the performance criteria and setting performance targets for enterprises adequately benchmarking them with similar enterprises in India and abroad. The paper highlights the issues and challenges in determining the performance targets under the MoU system and some best practices adopted by countries like China, South Korea, and others.
\end{abstract}

Keywords: performance contracts (PCs), performance target, performance benchmarking, memorandum of understanding (MoU)

Performance contracts (PCs) have been adopted by governments globally as tools to enhance performance of their state-owned enterprises (SOEs). A study conducted by the World Bank shows that more than 32 developing countries adopted the system of PCs and they have been termed differently by different countries like contrat-plan in France, the memorandum of understanding (MoU) in India, signaling system in Pakistan and so on (Shirley, 1995). All these contracts are negotiated and written agreements between governments and their enterprises with mutually agreed targets which the enterprises achieve within a given time frame. The system also defines the mechanisms for evaluating the performance within the specified period within a pre-determined institutional framework.

PCs have been broadly classified under two systems — the French based systems and the signaling system. The French system was followed by France, Africa (Senegal, Benin, and Morocco), and Latin America. Under this system, weights were not allocated to the targets which added a high degree of subjectivity to the evaluation process, while in the signaling system, signals were sent to the managers in order to monitor the results of the contacts. This system originated in Pakistan and Korea and was adopted by many Asian countries (Pakistan, South Korea, and Bangladesh), Africa (Ghana, Nigeria, and Gambia), and Latin America. Initially,

Corresponding author: Ram Kumar Mishra, Ph.D. in public finance, senior professor, director, Institute of Public Enterprise, Hyderabad, India; research fields: public sector policy and management, public finance, corporate governance, public private partnerships, and climate change. E-mail: ramkumarmishra@gmail.com.

Geeta Potaraju, Ph.D. in management, assistant professor, Centre for Governance and Public Policy, Institute of Public Enterprise, Hyderabad, India; research fields: good governance, public enterprise policy, citizen participation and governance tools, and public system studies. E-mail: pgeeta@ipeindia.org. 
the MoU system adopted in India was based on the line of French system; during its evolution, many features from the signaling system were adopted. Currently, the MoU signed between the public enterprises and the ministries consists of mission of the enterprise, its objectives, performance criteria, weightages assigned to each criterion and the period of contract and the mode of evaluation. The MoU system is based on the balanced score card approach, wherein all key factors in financial, financial are adequately represented.

The role and importance of these enterprises in a national economic growth changed considerably from being mere tools of fulfilling social objectives to being growth engines and contributing to economic prosperity of a nation. With the onset of the global financial crisis in 2008, for some countries, especially among the resource-rich emerging economies, the SOEs represented their main source of international capital as they accounted for one fifth of international mergers and acquisitions (Mehdi, 1985). The SOEs have emerged as an important source of international investment globally.

While there are some inherent problems that go along with these enterprises - they are usually very large in size with multiple control and accountability points which make them very difficult to govern. Therefore, the system of PCs was introduced at a time when many governments were facing troubles to manage performance of their enterprises. In this paper, the authors will focus on target setting process which is a key component of performance contracting system.

\section{Target Setting Process}

As a part of the process of PCs targets are set for both financial and non-financial parameters which are based on what the enterprise can reasonably achieve, given the expected policy environment, market situation, capital expenditures, and the level of delegation of financial powers to the enterprise. For each indicator, a rage of values is set so that performance can be graded, e.g., as excellent, good, fair, poor, or bad. There are some established methods for setting enterprise targets (Performance contracting for public enterprises, 1995).

(1) Inter-firm comparison: comparison of different firms in terms of their performance and profitability. Such a type of comparison is possible only when uniform costing is applied by all the firms which form a basis for comparison. The accumulated data regarding costs, prices, profits, etc., of different concerns are put in the form of consolidated statements and are made available to all the member-units so that they can make a comparative assessment of their achievements and weaknesses with those of others. This type of comparison helps in improvement in efficiency wherein each member-unit can try to improve its efficiency when on comparison with other member-firms it comes to know about its weak points. However, one of the key requirements of this method is the need for complete information;

(2) International comparisons of firms are not easy, because differences in market conditions, regulatory environment vary for each country. It is also not possible to comparison firms with other firms for monopoly enterprise, except where they are broken up regionally and the regional bodies can be compared. A combination of methods may be used for assessing public enterprises in each period.

(a) Trend analysis could be a basis for assessing performance improvement. If performance contracting is conceived as an instrument for progressive improvement of performance, then past performance adjusted for exogenous change is a sufficient standard. The Korean PCs make extensive use of regression analyses of past data. Seven-year time series analysis is made for most of the quantitative indicators. Form these, it is possible to project the expected targets for the following years, and also the standard deviation. This method is said to simplify target setting and reduce controversy. However, it rests on the assumption that the future will be a 
simple projection of the past;

(b) Yardstick competition is applied by a target-setter knowing the unit costs in simi1ar enterprises. In Bangladesh, for example, a detailed system of comparing cotton textile mills is used by the Bangladesh Textile Mills Corporation. The target is set by reference to the average enterprise, or the most efficient enterprise, taking the best performance on each activity. The United Kingdom Audit Commission has a tradition of "inter-firm" comparisons of local authority performance, which indicates that such comparisons may be valid and useful, despite disputes on their interpretation (Geeta, 2000);

(c) Work study and management audit is also used to set up targets, which represent reasonably efficient performance, though this method is slow and costly. The United Kingdom Monopolies and Mergers Commission (MMC) carries out in-depth review of efficiency as required by the Department of Trade and Industry. The MMC examines the trend of performance indicators, such as unit costs and quality, and management processes for want of valid international or intra-national comparisons of performance indicators, it tends to conform to widely accepted standards of management practices.

\section{Target Setting and Performance Evaluation of SOEs in India}

In India, the process of the target setting and evaluation begins with the: (1) Department of Public Enterprises first, releasing MoU guidelines in the month of October/November; (2) based on the guidelines, draft MoUs are prepared by enterprises and submitted to their administrative ministries; (3) examination of draft MoUs is done by the MoU division of the Department of Public Enterprises and documents are handed over to the members of the task force (technical expert group outside government set up to oversee the MoU process); (4) MoU negotiation meetings are scheduled between the enterprise and task force that begin from January/February; (5) negotiation meetings end up with finalization of the MoUs with the task force (January/March) each year; and (6) all MoUs are signed before March 31 of every year (Public Enterprises Survey 2011-12, 2011-2012).

\section{MoU Guidelines and Evaluation}

Every year, MoU guidelines are issued by the MoU division of the government, taking into account the dynamic and complex environment in which the public enterprises operate. Based on the guidelines, the enterprises prepare the draft MoUs and from there, the MoU is negotiated and finally, the MoU is signed. The $\mathrm{MoU}$ guidelines form the first step of the $\mathrm{MoU}$ cycle. $\mathrm{MoU}$ evaluation process is based on the "Balance Score Card" approach and is a combination of "financial" and "non-financial" targets, having equal weightage in the overall scores. In the case of sick and loss making enterprises, the guidelines try to focus more on the non-financial indicators rather than the financial indicators and the slightly alter the ratio of the financial to non-financial weights. A five point grading scale is used to grade the enterprises_- “excellent” to "poor”, based on the score they receive in the MoU score.

\section{Financial Targets}

Financial targets are specified and defined by the government in its guidelines and all enterprises are expected to adhere to these while choosing the financial targets without any deviation and a self certification is to be filled out by the enterprises to this effect. The guidelines are clear that the financial targets should be realistic, growth oriented, and aspirational. The targets must be, at the same time, consistent with the budget for 
the respective year and in conformity with those made by the Planning Commission, Ministry of Finance, Administrative Ministry/Department, and other statutory and regulatory bodies. In instances where the enterprises are found to be under-pitching, the task force or the Department of Public Enterprise will have the liberty to call upon their top management to give explanations for such under-pitching or gross over achievement. The basic targets are to be arrived at based on a combination of the performance of the enterprise over five preceding years and other factors such as: (1) capacity and its expansion; (2) business environment; (3) projects under implementation; (4) government policies; (5) external factors; and (6) company's growth forecast (MoU guidelines 2015-16, 2015-2016).

Another important factor to be considered for the basic financial targets is the national/international benchmarking. In the extant MoU system, the basic targets are generally expected to be an ambitious growth over the performance of the enterprise in the preceding year, however, if the performance of the enterprise is found to be bad in the previous year, then a more realistic target based on the average performance of the previous three years is to be taken into account.

\section{Non-Financial/Dynamic Targets}

The non-financial targets are a little more difficult to determine and the guidelines specify that the non-financial targets must be Specific, Measurable, Attainable, Result-oriented, Tangible (SMART).

Non-financial targets in the MoU should be in the following categories:

(1) Sector specific and enterprise specific targets;

(2) Initiatives for growth;

(3) Capacity addition;

(4) Project management and implementation;

(5) CAPEX-capital expenditure;

(6) Corporate Social Responsibility (CSR) and sustainability;

(7) Research and development;

(8) Human resource management;

(9) Risk management.

Corporate governance is a very important aspect in the existing system of $\mathrm{MoU}$, where there are negative marks and penalties in scores for any enterprise found to be in non-compliance of the corporate governance norms which were specified by the government and for listed companies the Security and Exchange Board of India (SEBI) guidelines. Similar penalties and negative markings are also applicable to the non-compliance of the CSR guidelines, Department of Public Enterprise (DPE), Government of India guidelines, and other forms of non-compliance.

\section{Grading}

The MoU system when first introduced was based on the French Contracting System and it was later changed to the "signaling system" after a year and after 2004-2005, it was further refined to the "Balance Score Card" approach. The performance of the enterprises in the MoU system is scored on a 5 point index which is calculated as the aggregate of all the "actual achievements" as against the targets set in the 5 point scale.

The grading is done based in the MoU "composite score” (see Table 1). 
Table 1

MoU Rating Scale

\begin{tabular}{|l|l|}
\hline MoU composite score & Rating \\
\hline 87.5 to 100 & Excellent \\
\hline Less than $87.5-67.5$ & Very good \\
\hline Less than $67.5-37.5$ & Good \\
\hline Less than $37.5-12.5$ & Fair \\
\hline Less than 12.5 & Poor \\
\hline
\end{tabular}

\section{Issues and Challenges in Target Setting}

Target setting process is one of the key activities of performance contracting system. A successful enterprise which is on the path of upward movement and aspires to be a leader in industry would adopt mechanisms for identifying realistic targets. Research has found out that SOEs world over have been grappling with this issue of target setting.

Broadly, the issues faced by enterprises can be categorized into the following:

\section{Determining Performance Levels}

There is a constant pressure on the management of public enterprises to raise the bar of performance each year. There is a general feeling among the enterprise managers that if they achieve a target in a year, their performance bar is raised in the next year. Therefore, there is a need to set realistic targets which can be achieved under given circumstances which have physical limits, such as capacity utilization, profitability, etc. Due to this reason, there is a tendency for the enterprises to set targets in such a way that it is very much within the reach of the enterprise. While setting targets, the enterprises make sure that their targets are neither too low which are easily achievable without effort nor too high which make them unachievable.

\section{Information Asymmetry}

Ideally, PCs must reduce the information advantage that enterprises have over the government and motivate enterprise officials through rewards or penalties (such as to pay bonuses or impose penalties) to achieve the targets (Shirley, 1995). In reality, the asymmetry of information between an enterprise and ministry allows the enterprise to get the targets it wants to set for itself. This asymmetry of information is taken advantage by the enterprise managers who use this information advantage to negotiate targets that were either hard for outsiders to evaluate or easy for them to achieve. In any case, performance is hard to evaluate, for example, when there are many targets or when targets change frequently or when the negotiations dragged on so long that targets were set equal to ex post performance, targets can be set soft.

The information advantage of the enterprise coupled with governments' failure to give the bureaucrats responsible for negotiating the contracts and evaluating results the power, resources, and status they needed to face enterprise managers at a level playing field leads to poor target setting. Enterprises are therefore able to negotiate targets that they could achieve without making additional efforts to improve productivity. Here is a good example, the Government of Pakistan (Geeta, 2000) provides guidelines for setting targets as mentioned below:

(1) Efficient target setting to carried out in a participatory process. Without this approach, targets tend to take the form of formal directives, which are often overtly accepted and covertly resisted;

(2) Targets to be clear-cut; 
(3) Targets to be neither too low nor high. This would give wrong signals to the managers;

(4) Each enterprise must be looked at in its own unique environment which must be taken into account;

(5) The targets must ensure that generation of surplus is significantly more than distribution by way of bonus;

(6) Targets must take into account the social tasks, which are taken up by the enterprises.

\section{Ownership Model}

The ownership model in the public sector, where politicians have many points of view and bureaucrats have many different agendas creates further problems in setting performance levels. Unlike the private companies, the public sector enterprises are susceptible to be used by political bosses for their personal benefits which may stand in contradiction to their progress to reach the declared performance targets.

\section{Strengthening Target Setting Process}

The success of the MoU exercise largely depends on the basic strength of target setting process. Such strength would largely depend on the initiatives outlined as under.

Generating continuous research evidence. Research evidence must be generated continuously for companies to set realistic as well as competitive targets as per their contracts. Empirical studies are carried out by countries to analyze the effect of such contracts on profitability and productivity and examine statistically the correlation between PCs and productivity so that evidence can be generated whether PCs actually improve efficiency. In a study conducted by the World Bank (Shirley, 1995), it found no pattern of improvement associated with the PCs in productivity or profitability trends. The study found no robust, positive association between PCs and productivity. An important question needs to be raised here-is it possible that PCs failed to improve productivity. A dedicated research group or an institution must continuously be involved in data collection from SOEs, conduct research and development for the benefit of SOEs, individually and collectively and disseminate results of study to all.

Strengthening governance mechanisms. Improving governance mechanisms go a long way in streamlining enterprise performance. Restructuring the board, which is driving force behind the success of an enterprise, is very critical. Research has shown that professionalizing the board improves the overall performance of enterprises especially in terms of achievement against the PCs. For example, Chile took up a successful experience in reforming its state enterprises and improving its efficiency as indicated below (Johnson \& Beiman, 2007).

(1) Chile increased competition by ending state monopolies and barriers to entry, reducing import tariffs to $10 \%$ across the board, breaking up monopolies in sectors as electricity, and pushing state enterprises to contract out competitive activities under strict rules of competitive bidding;

(2) It placed state enterprises under private commercial law, and members of the boards of directors became liable for their decisions;

(3) Private parties were named to boards, and boards were kept small (five people) to reduce the political value of keeping companies public;

(4) The government eliminated all subsidies, transfers, and government guarantees for debts of state enterprises and instructed banks to lend to them under the same criteria as for private enterprises;

(5) State enterprises were required to pay a $10 \%$ return on assets as a dividend, and money losers were required to sell assets to pay their dividend. 
Stakeholder participation. Stakeholder participation is the key for efficient target setting. Targets should be negotiated between the government and management and should not be imposed. The benefits of participation are not confined to the government management interface. It is apparent that improvement of performance can arise only by changes in behavior at the operating level. Therefore, there should be an internal dialogue through all levels of the enterprise extending the corporate goal and incentives to divisions and sections of the enterprise.

\section{Period of Contract}

Period of contract is equally critical for efficiency in target setting process. Planning encompasses a future period of time necessary to fulfill through a series of actions and commitments made and the availability of the capital.

In Gambia, for instance, PCs have been for four years. They spell out the goals of the enterprise, and autonomy for the management. The targets are separately negotiated each year and signed at the technical level. These are the basis on which annual performance is evaluated and rewarded or penalized. In India, targets are made annually coinciding with the annual plans of the enterprises. While some production companies accepted the time span of one year, the companies which are in the construction and exploration business express their views differently. They prefer the contracts to be for a longer period at least for 24-36 months, which is minimum time period for completion of a project.

\section{Strengthening Feedback Loop}

Performance contracting is a cyclical process in which results are fed back to the government and public enterprise. This is done in order to make correction for short-term variances form contract and this process is called monitoring. This could be represented by the feed-back loop of control.

\section{Case Study: Implementing Performance Incentives for SOEs in China}

Economic Value Added (EVA) is a tool designed to give managers of SOEs better information to make decisions that create the greatest shareholder wealth. While EVA implementation has been mainly studied in Western companies from the perspective of improving economic efficiency, we look at the great possibility of introducing EVA as a part of Performance Management System. Studies reveal that some changes in managerial behaviour have also been seen with EVA implementation (Li, 2012). An EVA based performance assessment policy was introduced by the State-owned Assets Supervision and Administration Commission of the State Council (SASAC), for 129 Chinese SOEs under direct administration of central government since 2010 as a part of the mission set out for SOEs under the 11th five-year plan (2006-2010) to "grow bigger and stronger". The study shows that by the end of 2010, the net profit achieved by the 122 Central SOEs reached 848.89 billion yuan, sizeable given that total profit by all China's SOEs was 21.37 billion yuan in 1998 . The Central SOEs listed in the Fortune 500 have increased from six in 2003 to 38 in 2011. SASAC as investor encourages central SOEs to emphasize on value-creating and maximizing shareholder value. EVA method is being implemented since 2010 which flows as follows:

EVA is the balance found by deducting the cost of capital from the net operating profit after tax (NOPAT), which reflects value created for shareholders in a certain period. Different from traditional financial indicator, EVA is the economic surplus calculated from shareholders' (investors') perspective, following shareholders' way to evaluate enterprise value. EVA is used as it could reflect the cost of debt capital and is calculated after 
the cost of equity capital is deducted from NOPAT.

Positive changes have been reported to central SOEs after SASAC applying EVA to performance assessment. This has led to building up value management system, prudent in investment decision-making, attach importance in capital management and attach importance in research and development investment. In 2003, the net profit (NP) of 183 central SOEs is RMB140.2 billion yuan (USD\$23 billion) with the rate of capital cost 5\%, the total EVA is only RMB6.7 billion yuan (USD\$1.1 billion). In 2014, the EVA of all the Central SOEs is RMB350 billion yuan (USD\$58 billion).

\section{South Korea Experience With Performance Evaluation System}

South Korea has a total of 303 institutions which are designated as SOEs under the Act on the Management of Public Institutions. The Koreans have experimented and fine tuned their performance evaluation system over the years and now has a well-structured and effective performance evaluation system for their SOEs. The first stage of the broad transition was between the years 1984 and 2003 where the performance of public corporations was introduced under which included the CEO (chief executive officer) performance evaluation and innovation evaluation. The second stage of the transition of the performance evaluation system was between 2004 and 2007 when the performance evaluation of quasi-governmental organizations was introduced in addition to evaluation of public organizations which evaluated the CEO performance, innovation and additionally, the auditor's performance was also evaluated. The last stage started from 2008 and continues presently which is the performance evaluation of SOEs system.

The broad monitoring system for SOEs in Korea has two parts. The first part is the performance evaluation system under which the following components of the SOEs are monitored, namely, SOE performance evaluation, CEO performance agreement and evaluation of the senior auditors. The second part of the monitoring of SOEs is the ALIO (All Public Information in One) system which is a system introduced to increase transparency through an information disclosure system.

The public institutions in Korea are evaluated by the Ministry of Strategy and Finance (MoSF) or the line ministries depending on the size and profitability of the corporations and organizations. The MoSF evaluates only the bigger public corporation or organizations which have self-generating revenue of more than $50 \%$ and also qausi-governmental organizations which have a self-generating revenue of less than $50 \%$. With regards to size, the evaluation of the corporations and quasi-governmental organization is done by the MoSF only in case, the total employment is greater than or equal to 50 people. Public institutions which are non-classified and have less than 50 employees are evaluated by their respective line ministries.

The evaluation of the SOEs is conducted by a Performance Evaluation Unit which is a temporary team consisting of about 160 experts from varied fields like academics and research analysts, etc. The MoSF also organizes an independent team to evaluate the performance. Once the evaluation team evaluates the performance of the public institutions, the results are finalized by the Committee for Management of PIs (Performance Indicators). The public institutions may also have complaints and policy suggestions which are directed to the Research Centre for state-owned entities which further suggests the system improvements to the MoSF which go to the committee for management of PIs where they are deliberated and resolutions are passed and finally, the evaluation team approves and finalizes the system improvements.

The system is based on a balanced evaluation between business administration and core businesses. There are two types of indicators against which performance of the SOEs are evaluated-quantitative and 
non-quantitative indicators which are divided on 65\%-35\% ratio. For business administration, non-quantitative indicators include strategy planning, financial management, remuneration and welfare benefits, while the quantitative indicators include business efficiency, government recommending policy. As regards core businesses, the non-quantitative indicators include plan activities and performances and quantitative indicators include plan activities and performances.

The results of the evaluation are divided into six grades after they are converted to scores on a 100 scale. The six grades are S (superior), A, B, C, D, E (inferior). Based on the results of the performance evaluation, the incentive rate is decided. The range of the incentive rate varies from $0 \%$ to $250 \%$ of the monthly wage, depending upon the grade received in the evaluation. SOE employees' incentives are determined by adding the institutional performance bonus and personal incentives. The Korean system also has a very unique penalty system where the MoSF in cases of low rated institutions may recommend the dismissal of CEO.

The evaluation system is linked to the incentive system (in the form of bonuses). The task force conducts the performance evaluation each year and the bonus size would vary between $0 \%$ and $500 \%$ of monthly wages depending on the evaluation results in the nine categories. The system also incorporates non-pecuniary incentives and sanctions. Awards are handed to the highest scoring enterprises while the enterprises that are performing poorly can have sanction (e.g., dismissal of top management) imposed on them. Finally, an important part of the entire system is the wide publicizing of the results of the performance evaluation in mass media. Public recognition plays an important role in Korean society and is a powerful motivational tool for performance of top management.

\section{Balanced Score Card (BSC) Approach}

The use of Balanced Score Card (BSC) Methodology for SOEs, is said to improve enterprise profitability, provide required guidance to enterprise managers using modern management concepts, methods, and tools, stimulate identification, analysis, and resolution of problems interfering with improvement of enterprise performance and most importantly build consensus and improves communication among management, employees, and stakeholders. The BSC tool is being used not only in developed economies, but in transitional economies as well. Having been successfully used to drive alignment and strategic results in the private sector, governments are increasingly using the BSC in government organizations and SOEs as part of an integrated strategy management process. Various types of SOEs use BSC tools to describe, measure, align, and manage their strategies.

Jinshan Telecom is a branch unit of China Telecom (an SOE) which has BSC as a tool for performance enhancement (Kaplan, 2001). Jinshan Telecom has four sections, 17 substations, and more than 20 retail service offices. In 2001, Jinshan's performance measurement and appraisal system did not reflect the company's strategic priorities. Jinshan Telecom's key performance indicators (KPIs) - another term used to describe the "measures" were not linked to the company's strategy. Each employee at Jinshan had 30-50 KPIs for which the employee was responsible. The numerous KPIs deterred employees from focusing on what was most strategically important. Moreover, it was difficult for the company to analyze, consolidate, or discuss the KPIs in management's efforts to execute their strategy more effectively. Further investigations found that Jinshan Telecom's cross departmental teamwork and cooperation was weak. The existing performance appraisal system lacked focus and did not align the organization horizontally across sections. The company adopted BSC Methodology and the BSC for Jinshan Telecom was cascaded down to all departments and 
individuals. As a result, company employees had clearer objectives, measures, and performance "targets". Also, a variable pay incentive system was established while deploying the BSC Methodology. This led to an increase in employee motivation for improving business results. The company achieved significant improvements in vertical and horizontal alignment, as well as significant improvements in cross-departmental teamwork and cooperation as a result of its BSC implementation.

Measurable improvements in quantitative performance, as reported by Mr. Xia Pei Yun, General Manager of Jinshan Telecom, included the following (Xia, 2003):

(1) Jinshan Telecom's 2003 growth rate was more than three times the Group Company's growth rate. Jinshan grew by $14 \%$, compared with the Group Company's 4\% growth rate (Jinshan was the first branch unit in the group company to deploy the BSC);

(2) Jinshan's superior growth rate was enabled by reaching or exceeding strategic performance targets in the customer, process, and learning areas;

(3) Jinshan's results on five performance measures met or exceeded targets: Key Account Satisfaction, Commercial Account Satisfaction, Repair Cycle Time, Connection to Internet Success, and Implementation of Planned Trainings.

\section{Total Factor Productivity}

Total Factor Productivity (TFP) is a composite measure of technological change and changes in the efficiency with which known technology is applied to production. The translog index of technology changes is based on a translog production function, characterization by constant returns to scale. In this method, two inputs Labour (L) and Capital (K) only, the total factor productivity growth (TFPG) can be estimated adequately. The studies show that growth in financial profitability is not necessarily always accompanied by an increase in TFP. Of the two, TFP is considered to be a superior method of evaluating performance. However, it is yet to gain acceptability in the SOEs as it does not support the managers' to stake high performance claim, benefit from financial incentives and projecting brighter image. The complexity of the method and lack of capacity on the part of the regulators and managers to implement it has hindered TFP its popularity (Mishra, Nandgopal, Geeta, \& Bulusu, 2001).

\section{Conclusions}

With the new government taking over in India in 2014, the focus has shifted on making the public enterprises more efficient and competitive so that they can face the stiff market competition. The MoU system is being made more transparent by using information technology and a new online MoU system is being designed and launched from the current year from October 2015-2016. This system will bring in greater scope for using the enterprise data for effective planning and decision-making by the government.

\section{References}

Geeta, P. (2000). Memorandum of understanding and public enterprises in India. PhD thesis. Submitted to Department of Business Management and Commerce, Osmania University, Hyderabad.

Johnson, C. C., \& Beiman, I. (Eds.). (2007). Driving performance and corporate governance. Asian Development Bank.

Kaplan, R. (2001). Integrating shareholder value and activity-based costing with the balanced scorecard. Balanced Scorecard Report.

Li, P. L. (2012). EVA adoption in SOEs: A case of revolutionary change. Middlesex University Business School, UK Guliang Tang, Narisa Tiangjing Dai, University of International Business and Economics, PRC, CGMA \& CIMA. 
Mehdi, I. (1985). Setting targets for improving cost efficiencies in PE's. Proceedings from the Conference on Cost Effective Management of PE's in Karachi. July 14, Karachi.

Mishra, R. K., Nandgopal, Geeta, P., \& Bulusu, N. (2001). Role of memorandum of understanding in public enterprise reforms. New Delhi: Vikas Publications.

MoU guidelines 2015-16. (2015-2016). Department of Public Enterprise, Government of India. Retrieved from http://www.dpemou.nic.in/MOUFiles/MoU_GL_2015-16.pdf

Performance contracting for public enterprises. 1995. Development Support and Management Services, United Nations, New York.

Public Enterprises Survey 2011-12. (2011-2012). Department of Public Enterprise, Government of India. Retrieved from http://dpe.nic.in/sites/ upload_files/dpe/files/survey1112/survey01/vol1ch8.pdf

Shirley, M. (1995). Why performance contracts for state owned enterprises haven't worked. World Bank Publication, Note No. 150, Public Policy for the Private Sector. Retrieved from http://siteresources.worldbank.org/EXTFINANCIALSECTOR/ Resources/282884-1303327122200/150shirl.pdf

Xia, P. Y. (2003). Using the BSC to implement performance management. At the First BSC Forum in China. December 19, Jin Mao Conference Center, Shanghai, China. 